\title{
ICT IN EDUCATION: ITS BENEFITS, DIFFICULTIES, AND ORGANIZATIONAL DEVELOPMENT ISSUES
}

\author{
Adi Suryani
}

\begin{abstract}
This essay describes some benefits of implementing ICT in classroom, especially within the area of collaborative and self-managed learning. However, implementing ICT in classroom is not an easy and simple matter. There are many issues which should be addressed. Those issues range from the school culture, teachers barriers, finance, leadership, curriculum, and ethical issues. Those problems are experienced by both developed and developing countries. This also refutes a widespread assumption that developing countries experience more barriers for implementing ICT than developed countries.
\end{abstract}

\section{Keywords: Collaborative Learning, Self-managed Learning Process, Technological Competition, Constructive Change, Technological Culture}

Recently, the development of ICT gradually replaces the traditional teaching pedagogy. Face to face classroom interaction is getting replaced by online communication, traditional white or blackboard is getting replaced by interactive whiteboard, and books or printed resources are getting replaced by online resources.

It is believed that technology can bring our education sector from the dark age to the light age. This is because the implementation of ICT in schools can bring about some potential benefits. However, to obtain those benefits we have to overcome its enormous difficulties. These difficulties may vary from school to school, from region to region, and from country to country.

It is frequently firmly believed by the developing countries that the most essential prerequisite of building prosperous nations is technological access, skills, and managements. We often assumed that what makes the developed countries developed is because they have good technological access, skills, and managements. This makes many developing countries see and learn what the developed countries do with their technology.

In reality, not only we as the developing countries face difficulties in integrating ICT into our schools sector, but also the developed countries. In some jsh Jurnal Sosial Humaniorah, Vol 3 No.1, Juni 2010 
respects, we have share similar difficulties, but in some others we face different difficulties.

The above phenomena will be the main discussion in this essay. The discussion in this essay is divided into four main parts. The first part covers the discussion of the benefits of ICT in teaching and learning area. The second part covers the discussion of the difficulties in western countries. In third part some examples of ICT implementation in western and eastern countries will be discussed. The last part covers the organizational issue in implementing ICT.

This study uses secondary data as the basis of its discussion. The use of secondary data in this discussion brings a benefit. As noted by Bryman (2004: 202) the use of secondary data allows us to make a journey exploring what other researchers have found, comparing and contrasting their findings to see the whole picture of what they have found.

\section{The Potential Benefits of ITC}

ICT can provide a considerable benefit in supporting learning. By using technology in their learning, the students can be active learners. They will be aware of what information they need, why they need it, and how they can get that information. As mentioned by Bransford, Brown, and Cocking (cited in Huffaker, 2003, p. 357) an active learning allows the students to decide when they require a particular information and whether they have already understood that information or not. This active learning also implies an independent learning. By having access to internet in their school the students will not totally depend on the teachers. They can explore information available in the internet, find information that they need, copy it, and go on to find more and more information. By using this learning system, the students also becomes self-managed in their learning process. As noted by Jarold and Sue (1992, p. 50) self-managed learning allows the students to be self-motivated and self-directed learners who will be able to readily, efficiently, and quickly respond to the quick change of information. The use of blog, for instance, can allow the educators and students to be very up-todate to the issues and discussion in educational sector or other sectors. Thus, we 
do not have to wait the newest revision of printed educational books or journal to know what happens in our educational sector for longer time.

ICT also can provide a way for dynamic and collaborative learning. By using internet our learning is not limited to the school hours, demographically where we are, and who our teachers are. We can access internet anytime and anywhere. As stated by Uhomoibhi (2006, p. 9) e-learning allows the students to get information faster from everywhere and anytime. Technology also enables us to cross the demography limits. Rural students can access information from urban areas, get information and share knowledge with other students or teachers in the same area or even different countries. Besides dynamic learning, ICT allows all the human components of schools; the principals, administrators, teachers, IT coordinators, and the students to get involved in the collaborative learning and forming learning communities. As mentioned by Moodiel (2000, p. 2) by working together we can do what we can not do individually.

The most important learning aspect in collaborative learning that we want to achieve using ICT is interactivity and communication. As mentioned by Rodrigues (2002, pp. 134-135) "effective learning happens when students are interactively engaged in a learning task." Learning using ICT is more than learning through memorization. It allows the learners to experience their learning processes, being interactive, enjoy and have fun with technology. As stated by Rodrigues (2002, pp. 136-137) by using technology to support collaborative learning, there will be not only human-machine interaction but also human-human interaction. Web-based-learning context, for instance, allows the students to interact with teachers or other students mediated by machine.

ICT can lead us to meta-cognitive learning. As noted by Monteith (cited in Monteith, 2002, p. 21) by using ICT in our learning we can learn how to learn rather than learn a particular skill. By this we can be realize that learning new technology and new knowledge is not more difficult than learning old knowledge/skills. This understanding is very vital since many people are afraid of learning new technology since they regard that learning something new (new technology) is more complex and difficult than the old ones. Frequently, in reality 
we can find that many new technologies are easier to learn and to operate than the old ones. The old wrong conception can be changed by implementing ICT in our learning. Paris and Winograd (cited in Phelps, Graham, and Kerr, 2004, p. 50) note that there are two important elements within meta-cognitive learning. Those are self-appraisal and self-management. Having self-appraisal, the learners can reflect and evaluate their own knowledge competency and development. Having self-management, the learners can plan, select, and use learning strategies which they prefer to gain knowledge.

ICT can improve children's literacy. As mentioned by Adonis (2006, p. 16) the effective use of ICT can upgrade the students' literacy and numeracy. Microsoft word, for instance, can motivate the children to learn writing skill. They can enjoy and being excited typing many new words using computer. It also can improve the children's speaking and listening skills. This is because they may work collaboratively with their peers, teachers, and parents/adults. Those children need to hear what others say to them and tell what they want to know. The children also can develop their reading skills by reading stories accessed trough internet. Thus, ICT plays an important role in scaffolding process to improve children's literacy.

The use of ICT not only can support the cognitive development of the students but also increase their motivation to learn and their interaction in learning. As noted by Davies and Birmingham (2002, pp. 19-20) identify three benefits of using storyboard program software, kar2ouche, to support the students' learning on Macbeth character. Those three kinds of benefits are cognitive, motivational, and interactional advantage. Cognitively, the students can retell what happen in the story without being told by the teachers. Motivationally, they enjoy and have fun with their learning process, so that learning is not painful and exhausted. Interactionally, they can work collaboratively with their teachers and peers.

\section{ORGANIZATIONAL DEVELOPMENT ISSUES FOR IMPLEMENTING} ICT 
Implementing ICT in classroom is not the matter of bringing the most modern technology to the schools and throwing all of the stuffs into classroom for the teachers to use it. This will not work effectively. As noted by Coppola (2005, pp. 4-9) the use of ICT in schools should not be trapped into "cosmetic use," "technological imperative," "romantic vision", or "technological competition." Cosmetic use of ICT happens when teachers feel that they are pressed to use technology in their teaching, even though they believe that using computer for teaching certain lesson is not the best method. They may say to theirself if I do not use technology in my class, others may see me as incompetent teacher. Thus, they are forecd to use technology in their class eventhough it is not really needed. Technological imperative traps schools when the school community becomes extremely enthusiatic about using technology in schools, no matter it is really useful or not. Schools are trapped in romantic vision when the schools believe that technology is better than teacher. They believe that technology can replace teacher in teaching. Technological competition occurs when a certain school achieves superior status just because it applies the most up-to-date technology without thoughtfully considering the education instructional design.

To make the use of ICT in education effective, then we have to consider some organizational aspects. Those are the schools' culture, the role of the leaders, the selection of the software/hardware, the school integrity or ethical issue, and school management system.

Many schools are rejecting the implementation of ICT because there is a mismatch between the schools' culture and the introduced software/hardware. As mentioned by Thomas (cited in Albirini, 2006, p. 51) "how acceptable a new technology will be in a society depends on how well the proposed innovation fits the existing culture." Thus, before introducing the new ICT in particular schools, we have to understand the schools' culture. More importantly we have to understand the intended value which the schools want to transmit to their students. The schools' community will reject the coming of the new technology if the introduced technology is not congruent with the schools' value. As mentioned by 
Hodas (1993, p. 9) all technology has its own value within it. Thus, a certain technology which is successful implemented in a particular school does not necessarily will be successfully implemented in the other schools. Besides there should be a congruency between introduced software/hardware and the schools' culture, the schools also should have an adaptive culture. As noted by Tearle (2004, p. 334) the adaptive culture allows the organization to be ready in accepting the constructive change within the organization.

The other consideration is getting the support of the leaders. The leaders have power to influence the teachers and other staffs to accept or refuse a certain technology. As noted by Yuen, Law, and Wong (2003, p. 161) the effective implementation of ICT basically is not depending on the kind of software but more depending on how the teachers can be empowered and influenced to use the software/hardware. One who can empower and influence them is the schools' leader. Thus, getting the leaders' /the principals' agreement is very vital. The principals are expected not only to support the implementation of ICT but also lead their followers in accepting, learn, and implement it in their schools (Moyle, 2006, p. 11). The principals also should be willing to learn the introduced software/hardware. They should give examples for the teachers how to accept and learn the new technology.

Consideration on the ethical issue relating to the use of technology is also very important. Schools are regarded as the place to grow moral integrity. The proposed ICT will be clearly rejected if the schools regard that that ICT will endanger the schools' integrity. For instance, internet access will open up an opportunity for the students to plagiarize or download pornographic sites. Thus, before deciding to allow the students to use internet, for instance, the schools' leaders should formulate the ethical code of using internet and computers, including prohibiting the use of computers to endanger others or spreading untrue information ("Internet Ethics," 2006, p. 5). The other important issue is involving the students to maintain the computer facilities. Many students do not care how to carefully operate the computers so that it can last longer. Even some of them steal 
the component of the computers. The schools should address this problem unless they should spend expensive cost to buy new computers again and again.

The ICT implementation should also be supported by good coordination and management system on the ICT application. Those are covering clear job specialization on who will be responsible to help teachers in class, monitor the progress of ICT in schools, or conduct ICT training. This aspect is very important since many teachers are reluctant to use technology in class because they frequently do not get immediate help when they stuck with computers in class. As mentioned by Tearle (2004, pp. 337-338) practical factors and attitude/ethos are two important factors for effectively implement ICT in schools. The practical factors include the management and coordination, the time availability of teachers and students, the availability of technology, sufficient training and school support. Attitude and ethos factors cover the perception and belief of each schools' member, and the schools' characteristics.

The other important organizational development issue is school policy that supports the use of ICT. OECD (2001, p. 15) mentions that to support ICT there should be a change in curriculum and schools' organizational structure. The traditional curriculum can not support ICT. It needs a fundamental change in curriculum.

\section{HOW TEACHERS CAN WORK HAND IN HAND WITH ICT?}

One of some central technological issues to implement ICT in classroom is a conventional assumption that technology will replace the role of teachers in class. What I should do in class if the students can browse all information/knowledge from the internet? Will my students see my role as their teacher less significant than technology if I use technology in my class? Those questions may be asked by some worry teachers.

Technology will not replace teachers' role. OECD (2000, p. 12) mentions that just like school which always be the formal place for teaching learning process, teachers will always play central role in teaching learning process. Teachers will always be needed in education. What will change is the role of 
tecahers. To work effectively with ICT in classroom, teachers should play different role. Elearningeuropa.info (2005, p. 1) mentions that the process of transferring knowledge is not from teacher to students anymore, but from students to students. This indicates that the teachers will not be the only source of all knowledge anymore, but they will be advisors, supervisor, and instructional providers for their students' learning process. This is supported by Newhouse (2002, p. 25) the teachers will always have authority to direct what their students should learn by using teaching instruction as well as creating learning environment. Implementing ICT in class means the teachers should be learning model. As mentioned by Committee on Development in the Science of Learning (cited in Newhouse, 2002, p. 25) the teachers should model the use of ICT as a media to find knowledge and scaffold the students.

Besides using ICT for scaffolding their students, teachers should use ICT for their profesional development. Using ICT in class demands teachers to have technical skill and knowledge besides their content subject knowledge. As stated by $\operatorname{OECD}(2000$, p. 16) "teachers must have a range of technical and pedagogical skills, with continuous up-dating to match advances in the technology and modes of use." Thus, teachers who use ICT in class has more duty; mastering their content subject, learning and alawys updating their technological skills.

\section{DIFFICULTIES IN IMPLEMENTING ICT EXPERIENCED BY WESTERN COUNTRIES/DEVELOPED COUNTRIES}

The developed countries, which are mostly generally perceived as hightech countries and have good technological management by many developing countries, may also experience some difficulties in implementing ICT in schools. Those difficulties may range from teachers' readiness, school supports, and finance.

Teachers play a vital role in successful implementation of ICT in class. As mentioned by Roblyer (cited in Lim and Khine, 2006, p. 97) how teachers perceive ICT can determine how well and effective the integration of ICT in class. 
Becta (British Educational Communications and Technology Agency) (2004, pp. 1-29) has analyzed some difficulties in implementing ICT in some developed countries, including UK, USA, Australia, Canada, Netherlands, and Hong Kong. It concludes some teachers in those countries refuse to use ICT because of some reasons. Firstly, the teachers are afraid of being embarrassed in front of their students if they cannot operate the machine or suddenly the technology does not work. They also may feel anxious if their students are more competent in handling technology than themselves. Secondly, the teachers feel that they are not competent due to the technological training. Some of them are "technophobic." Some of them are not serious in their training since they know that no matter how good they are in their training they will not be able to implement it in their schools. This is because their schools do not have sufficient technological facilities (Manternach-Wigans et. al, 1999, cited in Becta, 2004, p. 9). Becta also identifies some other difficulties in implementing ICT in schools of some developed countries. Those are insufficient access to technological resources (including insufficient hardware, bad management of resources, unsuitable software, low quality of hardware), the teachers' overload work, some technical problems, and some attitude and belief barriers (including unsupportive belief and negative assumption about the presence of ICT in classroom) (Becta, 2004, pp. 11-17)

In short, the difficulties of implementing ICT in class in some developed countries can be classified into:

\begin{tabular}{|c|c|}
\hline School Level Barriers & Teacher Level Barrier \\
\hline $\begin{array}{l}\text { - Insufficient Time } \\
\text { - Insufficient access to technological } \\
\text { resources } \\
\text { - Insufficient effective training } \\
\text { - Problems in its technical operation }\end{array}$ & $\begin{array}{l}\text { - Insufficient time (overload work of } \\
\text { the teachers) } \\
\text { - Has little confidence } \\
\text { - Technological refusal due to } \\
\text { negative perceptions } \\
\text { - Do not believe on the potential } \\
\text { benefits of ICT } \\
\text { - Insufficient personal access to }\end{array}$ \\
\hline
\end{tabular}


technological resources.

(Source: Becta, 2004, A Review of the Research Literature on Barriers to the Uptake of ICT by Teachers)

Australia also has specific difficulties due to the implementation of ICT in schools. Fleer (1989, pp.1-13) conducted a research to see how six Western Australian Schools perceive the implementation of microcomputers in their schools. She found some difficulties in implementing microcomputers in those schools. Firstly, the teachers get insufficient computer training. They also do not have computing educational background/skills. Secondly, there is insufficient school support. When teachers find problems with the technology in class, they do not get immediate help from the IT-coordinators. This makes many teachers are reluctant to use technology since stuck technology/machine can interrupt the teaching-learning process. Thirdly, there is lack involvement of the school leaders (principals). The unsupportive leaders may impede the successful implementation of ICT. Fourthly, frequently, the layout of classroom also can cause difficulty. Using computer/technology in class requires moveable chairs or flexible seat design which allows the students to work in groups and individually. Moreover, computers need to be placed in special class with certain temperature or other special environmental condition to make the computers last longer. Fifthly, the introduced and implemented software frequently is inappropriate to the school's culture, value, and students' need. As mentioned by Hodas (cited in Albirini, 2006, pp. 51-52) the school community will reject the proposed technology if there is a mismatch between the introduced technology with the school value. Many schools' IT-coordinators do not aware of this difficulty since frequently they think that the technology which should be implemented in their schools is the most up-to-date, the latest, or the most modern technology.

It is generally assumed by many developing countries that what makes many developed countries have very high-tech technology is because they are rich. They have unlimited fund to support their technological innovation and implementation. In reality, some literatures note that they also have difficulty in 
finance. As mentioned by Marshall and Taylor (2005, p. 7) the successful implementation of ICT in the developed countries also can be impeded by insufficient fund. This is similar to the report of the Commonwealth Tertiary Education Commission (CTEC) which was responsible to analyze the "efficiency and effectiveness of the application of the new technology in higher education in Australia in 1985." CTEC (cited in Steele, 1986, p. 131) finds that one of some barriers in implementing technology is relating to the issue of finance. Technology always changes rapidly. Frequently when we have not finished learning, implementing, or handling one technology, the other newer ones come. This can raise problem when the schools have a goal to keep the technologies in their schools always up-to-date. Maintaining the up-date-ness of technology needs a lot of finance. Some institutions have high finance to support the implementation of ICT, other institutions may do not have sufficient finance. This can open up a huge technological gap between the technologically advantaged and disadvantaged institutions.

\section{V.ICT APPLICATION IN DEVELOPED-DEVELOPING COUNTRIES OR WESTERN-EASTERN COUNTRIES: ITS POTENTIAL BENEFITS AND DIFFICULTIES.}

The developed-developing, western-eastern countries may share similar benefits of implementing ICT, but they may have different difficulties. This is because they have different contextual factors. They have different demography, technical expertise, technological culture, school organization, and economical condition. As mentioned by Pelgrum (cited in Becta, 2004, p. 23) every school in different countries may face different difficulty depending on its contextual factor. Below is the comparison of the application of ICT in developed and developing countries.

\section{A. DEVELOPED COUNTRIES:}

\section{- The Implementation of Wiki in Hong Kong}


On Choy and Chi Ng (2007, pp. 215-219) find some benefits and difficulties in implementing wiki in the Open University of Hong Kong. Firstly, It can support the social learning of the educators (tutors). They can up date and put the new teaching material in wiki. The tutors can share and get feedback from other tutors anytime and anywhere. Secondly, The educators (tutors) can get the newest information quickly. This makes them become up-to-date with the latest information/messages. Thirdly, wiki can support other teaching media such as flash. Moreover, the tutors feel enthusiastic with their webpage since they can design their own page. Forthly, the students also find great ease in accessing their tutors' teaching materials. They do not have to establish face to face communication anytime they want to get materials after or even before the class meeting. Fifthly, wiki allows them to work collaboratively. The students and tutors can be engaged in collaborative discussion. Sixthly, wiki support the sharing knowledge between learners without face-to-face interaction. Thus, the process of sharing knowledge can occur more quickly.

In spite of its benefits, the implementation of wiki in Hong Kong encounters some real difficulties. Firstly, they encounter problems with its technical operation. Some tutors and students find that it is difficult to operate wiki since they have not familiar with wiki yet. Their unfamiliarity is caused by their reluctance to learn wiki as something new. This is because of the assumption that learning something new (new technology) is more difficult than learning the old technology. The second problem is an interactivity problem. Even though the students realize that wiki can allow them to work collaboratively with their peers and tutors, many of them do not communicate using wiki since they get used using old technology/OLE (Online Learning Environment, covering web-based email and other electronic systems). They also do not have sufficient time to learn new wiki since they prefer to spend more time for concentrating to the substantive content of their subjects. Thirdly, some of the students my think that wiki software is not suitable with their substantive subject. This is because some subjects can be better delivered by using technology, while others cannot.

\section{- E-Learning in public high-schools in UK}


The implementation of e-learning in UK can provide considerable benefits as well as can cause some difficulties. Huffaker (2003, p. 358) identifies some of its benefits. Those are:

\begin{tabular}{|c|c|}
\hline \multicolumn{2}{|c|}{ The benefits of e-learning } \\
\hline $\begin{array}{l}\text { Being actively engaged in } \\
\text { learning }\end{array}$ & $\begin{array}{l}\text { The learners are aware of their own learning. This } \\
\text { means they know what knowledge they need and } \\
\text { how they will get that knowledge }\end{array}$ \\
\hline Supports social learning & $\begin{array}{l}\text { E-learning provides opportunities for the learners } \\
\text { to work together/collaboratively without being } \\
\text { limited by environment/demography aspect. The } \\
\text { learners can build learning community. }\end{array}$ \\
\hline $\begin{array}{l}\text { Gives an opportunity for the } \\
\text { teachers to give continuous } \\
\text { feedback }\end{array}$ & $\begin{array}{l}\text { In e-learning teaching-learning process will not } \\
\text { be slowed down to wait the slower learners } \\
\text { understand the knowledge. Teachers will be able } \\
\text { to guide learning process based on each learner's } \\
\text { learning speed. }\end{array}$ \\
\hline Transfer of learning & $\begin{array}{l}\text { E-learning opens up opportunity for the students } \\
\text { to communicate and learn from others without } \\
\text { having face-to-face interaction. }\end{array}$ \\
\hline $\begin{array}{l}\text { Scalability and } \\
\text { Modularisation }\end{array}$ & $\begin{array}{l}\text { E-learning is very flexible. It can accommodate } \\
\text { from small number to huge number of } \\
\text { participants without drastically affects its cost. }\end{array}$ \\
\hline
\end{tabular}

In spite of some of its benefits, e-learning in UK has some potential difficulties. Some of those difficulties are:

\begin{tabular}{|l|l|}
\hline \multicolumn{1}{|c|}{ Difficulties } & \multicolumn{1}{c|}{ Causes } \\
\hline Enormous cost & $\begin{array}{l}\text { The school has to provide internet access, } \\
\text { computers, and training for the teachers. }\end{array}$ \\
\hline Teachers' refusal & - The teachers may not be confident in using \\
\hline
\end{tabular}




\begin{tabular}{|l|l|}
\hline & $\begin{array}{l}\text { technology in class. } \\
\text { - The teachers are afraid of experiencing } \\
\text { technological stress, which is probably heard } \\
\text { from their colleagues' experiences } \\
\text { - They may feel embarrassed if their students } \\
\text { have higher technological competency than } \\
\text { them. } \\
\text { - Negative perceptions on ICT }\end{array}$ \\
\hline Standardisation & $\begin{array}{l}\text { The school has to be able to integrate the e- } \\
\text { learning with the previous hardware/software } \\
\text { structure, meet some established standards. }\end{array}$ \\
\hline Academic dishonesty & $\begin{array}{l}\text { It will be very difficult for the teachers to } \\
\text { monitor whether their students cheat or not, } \\
\text { plagiarize or not }\end{array}$ \\
\hline Filtering software & $\begin{array}{l}\text { To avoid the students form the danger of } \\
\text { pornographic sites, the school should provide } \\
\text { software filterer. This action may lead to the } \\
\text { students' disagreement since the students feel } \\
\text { being distrusted. They also may feel that their } \\
\text { school invades their privacy. }\end{array}$ \\
\hline
\end{tabular}

\section{B.DEVELOPING COUNTRIES:}

- The use of computer and internet access to support English language teaching in Malaysia

Some developing countries also encounter some difficulties in integrating ICT into schools. Malaysia, for instance, also find some difficulties in implementing ICT. Even though it knows that ICT can bring a considerable potential benefits, but frequently greater barriers block these benefits. Thus, before gaining the benefits, it has to pass through great difficulties. Malaysia, as one of some developing countries, also experiences the same thing. As reported 
by Samuel and Bakar (2006, pp. 5-14) there are some benefits in using ICT for supporting the English language teaching. Firstly, it can increase the students' English grade. This is because the students can work collaboratively, they can help each other. They are more motivated to learn and find that learning English is interesting since they can access interesting quiz from web. Secondly, learning is not limited by time and space since the students can access the material anytime. Thirdly, the students can learn more independently. This is a great benefit since culturally the eastern students are accustomed to depend their leaning on their teachers. If they get good teachers they will be good and intelligent students, but if they get bad teachers they may become lazy and bad students.

However, those potential benefits are impeded by an enormous difficulty. Some of those difficulties are:

\begin{tabular}{|c|c|}
\hline Difficulties & Causes \\
\hline Technological barrier & $\begin{array}{l}\text { - Lack of computers facilities. Thus, the } \\
\text { students have to take their turn/have to wait if } \\
\text { they want to use computers. This can de- } \\
\text { motivate them. } \\
\text { - There is no proper maintenance for the } \\
\text { existing computers } \\
\text { - The signal of the internet is not consistent. } \\
\text { - There is no central database }\end{array}$ \\
\hline Teachers barriers & $\begin{array}{l}\text { - The teachers are not provided with personal } \\
\text { computers } \\
\text { - Lack of computer training for the teachers } \\
\text { - The teachers' poor computer skills } \\
\text { - The teachers' overload work } \\
\text { - Negative assumption on ICT }\end{array}$ \\
\hline School support barriers & $\begin{array}{l}\text { - The school principal does not provide } \\
\text { enthusiastic support to the teachers to use }\end{array}$ \\
\hline
\end{tabular}


technology in class

- The manual administrative wok increases the work load of the teachers.

- The Implementation of windows movie maker in secondary schools in Indonesia

Implementing ICT in schools, especially many public schools in Indonesia also will offer some potential benefits and difficulties. Implementing windows movie maker, for instance, will provide some benefits. Firstly, it can encourage the teachers, the IT coordinators, and the students to get involved in collaborative work, help each other. Secondly, it can stimulate the students to learn visually and auditorily since the students can see as well as listen to its presentation (the window movie maker). Thirdly, it can stimulate the students/learners to be creative by creating attractive/interesting movie by their own. Forthly, the students can feel the challenge of making their own movie, revise it, and feel excited when they can see that they can create excellent movie.

However, there are also some potential difficulties that may hamper the above potential benefits. Some of those barriers are:

\begin{tabular}{|l|l|}
\hline \multicolumn{1}{|c|}{ Difficulties } & \multicolumn{1}{c|}{ Causes } \\
\hline Technological & - Lack of computer facilities. There are some schools \\
& which do not have computer facilities at all. \\
- The schools only have some old computers. These \\
computers frequently work very slowly and the \\
students become impatient and de-motivated in \\
using computers. Moreover it takes long time. \\
- There is no maintenance. Many of the teachers only \\
know how to operate it. Many of them even do not \\
know how to operate it safely. \\
\hline Teachers' refusal & - Teachers are afraid of being embarrassed if they do \\
& not know how to operate a sudden stuck computers \\
\hline
\end{tabular}




\begin{tabular}{|c|c|}
\hline & $\begin{array}{l}\text { - Many senior lecturers will keep their status quo, } \\
\text { keep the traditional pedagogy, and influence the } \\
\text { junior teachers to reject the implementation of ICT } \\
\text { - Teachers also may be afraid of being replaced by } \\
\text { computers } \\
\text { - Teachers may perceive that by using machine in } \\
\text { their teaching, the teaching process will be too } \\
\text { mechanized, everything will be strictly controlled } \\
\text { and depend on computers/machines. }\end{array}$ \\
\hline Financial difficulties & $\begin{array}{l}\text { - Many public schools receive only a small amount of } \\
\text { subsidy from the government. These schools are not } \\
\text { able to buy computers or run its maintenance. }\end{array}$ \\
\hline Students' refusal & $\begin{array}{l}\text { - They may do not have computers at home. Thus, } \\
\text { they have to use computers at schools } \\
\text { - They also may find difficulty in getting access to } \\
\text { computers at school. They have to book it one or } \\
\text { some days before and that is only one or one and } \\
\text { half hours. } \\
\text { - They may say that learning windows movie maker } \\
\text { is not their substantive subjects, so they are not } \\
\text { serious to learn and feel that they "do not have to be } \\
\text { able." }\end{array}$ \\
\hline $\begin{array}{l}\text { School organizational } \\
\text { issues }\end{array}$ & $\begin{array}{l}\text { - Many schools' leaders are senior teachers who } \\
\text { prefer to use and more appreciate the traditional } \\
\text { pedagogy } \\
\text { - Many computer coordinators frequently are not } \\
\text { willing to share their computer skills/knowledge } \\
\text { with the teachers since they are afraid that their } \\
\text { teachers will be more competent and replace them. } \\
\text { - Many schools firmly believe "technology is just a }\end{array}$ \\
\hline
\end{tabular}


tool, thus it will be all right for us if we do not have it." As the result, those schools do not try to use technology in classroom at all.

\section{VI.CONCLUSION}

Implementing ICT in schools/education has many benefits and difficulties. Each school has its own barriers depending on its contextual factors. Generally the difficulties can be classified into four kinds of barriers. Those are technological barriers, teachers' refusal, students' refusal, and poor schools' technological system.

To successfully implement ICT in schools need to consider many aspects. It will waste a lot of time, energy, and money if before implementing it, we do not consider those aspects. Those are the schools' culture, leaders, ethics, and technological management system.

\section{REFERENCE LIST}

Abbott, J., \& Dahmus, S. (1992). Assessing the appropriateness of self-managed learning. The Journal of Management Development, 11 (1), 50-60.

Albrini, A. (2006). Cultural perceptions: The missing element in the implementation of ICT in developing countries. International Journal of Education and Development Using Information and Communication Technology, 2 (1), 49-65.

Adonis, L., A (2006). Technology in schools. The British Journal of Administrative Management, 14-15. 
British Educational Communications and Technology Agency (Becta), (2004). A review of the research literature on barriers to the uptake of ICT by teachers. Retrieved from http://www.becta.org.uk.

Copolla, E., M. (2005). Powering up: Supporting constructivist teaching with technology. Paper presented at the National Educational Computing Conference, Philadelphia, Pennsylvania.

Davies, C., \& Birmingham, P. (2002). Using ICT to enhance the learning experience in the classroom. Education Libraries Journal, 45 (1), 17-19.

Elearningeuropa. Info (2005). The new learning paradigm in school education. Retrieved from http://www.elearningeuropa.info

Fleer, M. (1989). A cross-cultural study of the implementation of microcomputers into schools. Australasian Journal of Educational Technology, 5 (1), 1-13.

Hodas, S. (1993). Technology refusal and the organizational culture of schools. Education Policy Analysis Archives, 1 (1), 1-23.

Huffaker, D. (2003). Reconnecting the classroom: E-learning pedagogy in US public high schools. Australian Journal of Educational Technology, 19 (3), 356-370.

Internet ethics. (2006). Leadership for Students Activities, 34 (9), 4-6.

Lim, C., P. \& Khine, M., S. (2006). Managing teachers' barriers to ICT integration in Singapore schools. Journal of Technology and Teacher, 14 (1), 97-125. 
Marshall, S. \& Taylor, W. (2005). Facilitating the use of ICT for community development through collaborative partnerships between universities, governments, and communities. International Journal of Education and Development Using Information and Communication Technology, 1 (1), 512.

Monteith, M. (ed.) (2002). ICT: Teaching primary literacy with ICT. Buckingham: Open University Press.

Moodiel, P. (2007). Creating support and teacher relationship. Retrieved from http://www.icte.org/SA_library-index.html.

Moyle, K. (2006). Leadership and learning with ICT. Voices from the profession. Teaching Australia. Australia: Australian Institute for Teaching and School Leadership LTD.

Newhouse, C., P. (2002). The impact of ICT on learning and teaching. Perth: Specialist Educational Services.

OECD, (2001). Learning to change: ICT in schools. Paris: Organisation for Economic Co-operation and Development

On Choy, S. \& Chi Ng, K. (2007). Implementing wiki software for supplementing on-line learning. Australasian Journal of Educational Technology, 23 (2), 209-226.

Phelps, R., \& Kerr, B. (2004). Teachers and ICT: Exploring a metacognitive approach to professional development. Australasian Journal of Educational Technology, 20 (1), 49-68.

Rodrigues, S. (2002). Opportunistic challenges. Teaching and learning with ICT. New York: Nova Science Publishers, Inc. 
Samuel, R., S. \& Bakar, Z., A. (2006). The utilization and integration of ICT trends in promoting English language teaching and learning: Reflections from English option teachers in Kuala Langat District, Malaysia. International Journal of Education and Development Using Information and Communication Technology, 2 (2), 4-14.

Seele, J. (1986). Edtech and the review of efficiency and effectiveness in higher education. Australian Journal of Educational Technology, 2 (2), 129-138.

Tearle, P. (2004). A theoretical and instrumental framework for implementing change in ICT in education. Cambridge Journal of Education, 34 (3), 331351.

Uhomoibhi, J., O. (2006). Implementing e-learning in Northern Ireland: Prospects and challenges. Campus-Wide Information Systems, 23 (1), 4-14.

Yuen, A., H., K., Law, N., \& Wong, K., C. (2003). ICT implementation and school leadership. Case studies of ICT integration in teaching and learning. Journal of Educational Administration, 41 (2), 158-170. 